\title{
Formation of Top Job Skills of Tomorrow Among Computer Engineering and Information Technologies Undergraduate Students in the Process of Learning English
}

\author{
Oleksandr Malykhin \\ Department of Didactics \\ Institute of Pedagogy of NAES of \\ Ukraine \\ Kyiv, Ukraine \\ malexvladi@gmail.come
}

\author{
Nataliia Aristova \\ Department of International \\ Relations and Research Cooperation \\ Institute of Pedagogy of NAES of \\ Ukraine \\ Kyiv, Ukraine \\ n.aristova.na@gmail.com \\ Nataliia Dyka \\ Department of Primary Schoold \\ Education \\ Kryvyi Rih State Pedagogical \\ University \\ Kryvyi Rih, Ukraine \\ fasollka@i.ua
}

\author{
Nataliia Dichek \\ Department of History and \\ Philosophy of Education \\ Institute of Pedagogy of NAES of \\ Ukraine \\ Kyiv, Ukraine \\ n.p.dichek@gmail.com
}

\begin{abstract}
The main aim of the study was to investigate Computer Engineering and Information Technologies undergraduate students' attitude towards the most important job skills of tomorrow and to provide methodology for their enhancing in the process of learning English. To collect data essential for developing methodology aimed at enhancing top job skills of tomorrow in the process of learning English, 295 Computer Engineering and Information Technologies undergraduate students aged from 17 and 21 were selected to take part in the web-based survey. In total, research sample was presented by 64 female students and 231 male students. The team of researchers developed the educational content of the English elective course targeted at developing top job skills of tomorrow among undergraduate students. Taking into account the fact that English holds great didactic potential for developing knowledge, skills and aptitudes among students of different specialties at higher education institutions necessary for reaching success in the future, the educational content of the English elective course is oriented towards increasing motivation to master English among undergraduate students of the mentioned specialties, on the one hand, and to boost the identified job skills of tomorrow,
\end{abstract}

on the other hand. The realization of the proposed educational content is based on the integration of the fundamental principles of action-oriented, competencebased, mastery-based and project-based approaches. Considering English as an efficient medium of instruction we can suggest the following idea: upgrading the educational content can provide endless opportunities for professional development of undergraduate students. To be exact, on their way of gaining professionally valuable knowledge and skills generally subdivided into two groups (soft skills and hard skills) they are involved in the activities that could guarantee the development of abovementioned skills. Thus, the created English elective course could serve as an example to follow.

Keywords - Computer Engineering and Information Technologies undergraduate students, English elective course, English as a medium of instruction, top job skills of tomorrow. 


\section{INTRODUCTION}

A review of scientific literature indicates that the majority of contemporary scholars and practitioners begin to embrace the concept that to take a rightful place in the ever-changing society young people have to acquire a wide range of lifelong learning skills while studying and academic institutions of different levels must play an important role in this endeavour [1; 2; 3]. In the light of various momentous events that have already disturbed the human conscience it is obvious that knowledge on universal values and their influence on the process of forming lifelong learning skills and competences, a set of soft skills and job skills of tomorrow among current and future generations of professionals may become a strong basis for building a cohesive world community. In that context, university education has an invaluable role to play. To live in peace and harmony for years to come people around the world should acquire knowledge and skills that will enable them to respond rapidly to changes that are constantly happening in the world. This will be possible only if the content of university programs takes into account trends in various spheres of the world economy and is aimed at equipping students with job skills of tomorrow anticipating their importance. To withstand global upheavals brought about by natural and man-made disasters people all over the world should act collectively regardless of professional, ethnic or religious affiliation. This is most evident now when all the nations of the world have expressed their willingness to help each other in combating the Covid-19 pandemic placing the highest value on the person. In this regard universities and nearest future university education can play a crucial role not only in training highly competent specialists but in creating global citizens sharing common universal values.

Considering the ideas declared the value of learning and mastering English strengthens greatly and the proper knowledge of English becomes an effective way and means for communicating and exchanging innovative ideas concerning the problems of the globalised world. That can also be regarded as one of the important objectives of the professional development of Computer Engineering and Information Technologies undergraduate students. The problem of upgrading the learning content of English as an obligatory (or an elective) course converts into being mainstream. And the perspective to guarantee an effective solution to the problem discussed the team of researchers sees in combining the objectives of learning and mastering English and in providing the actual and up-to-date professionally-valuable content for learning and mastering English as an essential means for enhancing top job skills of tomorrow among undergraduate students. In most universities all over the world in the countries where English is not the first or the second official language, the English course as an academic discipline is included into university training programs. And that is one more powerful reason for concentrating our attention on forming top job skills of tomorrow among undergraduate students of mentioned specialties in the process of learning English. So, taking into account the fact that English holds great didactic potential for developing knowledge, skills and aptitudes among students of different specialties at higher education institutions necessary for reaching success in the future, the educational content of English as an elective (or obligatory) course could be oriented towards increasing students' motivation to master English, on the one hand, and to boost the development of the identified job skills of tomorrow, on the other hand.

To fulfil themselves as highly qualified professionals along with profound theoretical knowledge future entrants into the world and national labour markets need to acquire various skills while studying at universities [4; 5]. According to World Economic Forum 2020 [6], the important job skills of tomorrow that will enable young people not only to survive in our rapidly changing world but to succeed are presented in four categories, each of which contains different skills: problem-solving, working with people, self-management, technology use and development. Thus, analytical thinking and innovation; complex problem-solving; critical thinking and analysis; creativity, originality and initiative and reasoning, problem-solving and ideation belong to the Problemsolving category. The Self-management category encompasses such skills as active learning and learning strategies and resilience, stress tolerance and flexibility. Leadership and social influence skills are linked to the Working with people category. Technology use, monitoring and control skills and technology design and programming skills are associated with the Technology use and development category. It should be noted that our research which drew from the abovementioned classification was aimed to investigate Computer Engineering and Information Technologies undergraduate students' attitude towards the most important job skills of tomorrow and on the basis of the obtained results to provide methodology for enhancing the identified skills in the process of learning English.

\section{MATERIALS AND METHODS}

The team of researchers carried out the exploratory study targeted at investigating Computer Engineering and Information Technologies undergraduate students' attitude towards the most important job skills of tomorrow and providing methodology for their enhancing in the process of learning English. The data the researchers were interested in were collected between October and December 2020 via online Google Form. The choice of an online survey through the distribution of the developed Google Form is explained by the need to comply with the coronavirus control measures taken and 
Environment. Technology. Resources. Rezekne, Latvia Proceedingsofthe $13^{\text {th }}$ InternationalScientificandPractical Conference. Volume 2, 249-254

to follow stay-at-home orders to slow the spread of Covid-19.

The sample of the study included 295 Computer Engineering and Information Technologies undergraduate students aged from 17 and 21: 64 female (21.70\%) and 231 male (78.30\%) participants. The sample was selected by applying a convenience sampling method and the link to the developed Google Form was sent to undergraduate students of the mentioned specialties who studied at Kyiv National University of Technologies and Design (Kyiv, Ukraine) and Interregional Academy of Personnel Management (Kyiv, Ukraine). The respondents' participation in the online survey was voluntary. All the respondents were informed that the data were collected only for one reason to find out their attitude towards the most important job skills of tomorrow and on the basis of the data received to provide methodology for enhancing the identified skills in the process of learning English.

The team of researchers developed a web-based questionnaire using the Google Forms web app. All the participants who agreed to take part in the online survey completed the proposed questions including sociodemographic information and questions aimed at finding out their attitude towards the most important job skills of tomorrow. The participants were also asked to rate the importance of top job skills of tomorrow on a 5-point Likert-type scale (5 - extremely important; 4 - very important; 3 - moderately important; 2 - slightly important; 1 - not important). The list of proposed job skills included analytical thinking and innovation; active learning and learning strategies; complex problemsolving; critical thinking and analysis; creativity, originality and initiative; leadership and social influence; technology use, monitoring and control; technology design and programming; resilience, stress tolerance and flexibility; reasoning, problem-solving and ideation. The respondents were also asked whether the mentioned job skills of tomorrow were being developed at university and to explain what way the identified skills would help them reach their full potential.

254 respondents $(86.10 \%)$ provided answers to the open-ended questions which enabled the researchers to summarize statements frequently occurring in their comments.

The obtained results were analysed qualitatively and quantitatively in order to provide methodology for enhancing job skills of tomorrow in the process of learning English.

\section{RESUlTS AND DISCUSSION}

Table 1 demonstrates the research results obtained among Computer Engineering and Information Technologies undergraduate students.
TABLE 1 RESPONDENTS' OPINION ON THE IMPORTANCE OF JOB SKILLS OF TOMMOROW FOR PURSUING THEIR

CAREERS

\begin{tabular}{|c|c|c|c|c|c|}
\hline $\begin{array}{c}\text { Ten Job Skills of } \\
\text { Tomorrows }\end{array}$ &  & 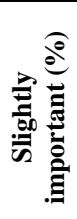 & 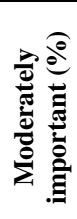 & 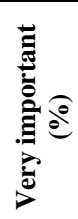 &  \\
\hline $\begin{array}{l}\text { Analytical thinking } \\
\text { and innovation }\end{array}$ & 0.00 & 0.00 & 25.00 & 25.00 & 50.00 \\
\hline $\begin{array}{l}\text { Active learning and } \\
\text { learning strategies }\end{array}$ & 0.00 & 0.00 & 20.00 & 35.00 & 45.00 \\
\hline $\begin{array}{l}\text { Complex problem- } \\
\text { solving }\end{array}$ & 0.00 & 0.00 & 15.00 & 25.00 & 60.00 \\
\hline $\begin{array}{l}\text { Critical thinking and } \\
\text { analysis }\end{array}$ & 0.00 & 0.00 & 5.00 & 20.00 & 75.00 \\
\hline $\begin{array}{l}\text { Creativity, originality } \\
\text { and initiative }\end{array}$ & 0.00 & 0.00 & 20.00 & 25.00 & 55.00 \\
\hline $\begin{array}{l}\text { Leadership and social } \\
\text { influence }\end{array}$ & 0.00 & 0.00 & 10.00 & 25.00 & 65.00 \\
\hline $\begin{array}{lr}\text { Technology } & \text { use, } \\
\text { monitoring } & \text { and } \\
\text { control } & \\
\end{array}$ & 0.00 & 0.00 & 0.00 & 40.00 & 60.00 \\
\hline $\begin{array}{l}\text { Technology design } \\
\text { and programming }\end{array}$ & 0.00 & 0.00 & 5.00 & 30.00 & 65.00 \\
\hline $\begin{array}{lr}\text { Resilience, } & \text { stress } \\
\text { tolerance } & \text { and } \\
\text { flexibility } & \\
\end{array}$ & 0.00 & 0.00 & 5.00 & 45.00 & 50.00 \\
\hline $\begin{array}{l}\text { Reasoning, problem- } \\
\text { solving and ideation }\end{array}$ & 0.00 & 0.00 & 0.00 & 40.00 & 60.00 \\
\hline
\end{tabular}

The results obtained and presented in Table 1 enabled us to make a conclusion that the majority of respondents considered the identified job skills of tomorrow as essential for pursuing their career. And this is obvious considering the statements declared in the materials of the World Economic Forum 2020 [7]. Thus, the main idea expressed is that by 2025 more than half of the labour force of the world will need re-skilling. The second idea is that in the next five years the significance of such skills as critical thinking and problem-solving will be increased greatly. To be able to respond quickly to the present-day challenges employees will need to be resilient, stress tolerant and flexible. They will have to become active learners and display a wide range of lifelong learning skills. What is more, it can take up to six months to re-skill around $40 \%$ of labour force all over the world [8].

Thinking about lifelong learning and lifelong learning skills, Peat, Taylor and Franklin come to the conclusion that the paramount task of any present-day university is to equip its graduates with knowledge and skills that will enable them to respond promptly and effectively to all the changes in the labour market because students' "ability to learn tomorrow is as important as the ability to learn today” [9, p. 135].

The similar idea is expressed by Laal and Salamati who are convinced that a person who is equipped with 
lifelong learning competences and skills “will keep up with society by staying current and aware of changes in such areas as technology, news and political trends or finance and money issues” [10, p. 403].

Peat, Taylor and Franklin propose their own classification of lifelong learning skills that includes eight categories: communication, interpersonal, information management, research, perspectives, business and personal [11, p. 146]. What is more, scholars suggest innovative teaching practices aimed at developing generic lifelong learning skills successfully implemented into biology courses at the University of Sydney. Among the innovative teaching practices special importance is given to the virtual learning environment, the online tutorial and assessment modules, and online discussions with large groups of students. The scholars are convinced that since the virtual learning environment enables to take into consideration students' learning styles it is very effective in developing their lifelong learning skills. The online tutorial and assessment modules are focused on the improvement of students' independent learning skills, and online discussions are useful in practicing students' thinking and communication skills.

We cannot fail to agree with the idea contained in the paper by Kommers and Fischer that for today "Lifelong learning is more than adult education and/or training — it is a mindset and a habit for people to acquire” [12, p. 3]. It means that university graduates equipped with lifelong learning skills will be better prepared to cope with changes in society. The scholars insist that to be successful in developing lifelong learning skills among university students, university lecturers should organise instruction within the context of authentic problems and learning-on-demand needs. Moreover, organizational and collaborative learning must be provided taking into account the fact human mind has some limitations.

Responding to the question concerning the development of the identified job skills of tomorrow at university the majority of Computer Engineering and Information Technologies undergraduate students replied (92.00\%) that although these skills were being developed the process had to be intensified and university lecturers should use more interactive methods and techniques.

Explaining what way the identified job skills of tomorrow would help to reach their potential the majority of respondents (87.00\%) reported that they would be able to prove themselves as highly qualified professionals and contribute greatly to the communities they were a part of.

Based on the obtained results we can state that when providing upgraded university training programmes as being adapted to meet the requirements of current conditions of global development (and, moreover, influenced by such unpredictable impacts as the Covid-19 pandemic) the scholars should take into consideration the following issues, to be exact: 1) orientation towards simultaneous development of students' hard and soft skills on their way of gaining professionally-valuable knowledge; 2) seeing the development of a set of lifelong learning skills and competences, a set of soft skills and top skills of tomorrow as one of the most important implicated objectives of future specialist' professional training; 3) organizing the training process within some certain academic disciplines (humanities are preferable) targeted at gaining knowledge on the content essence and the functionality of the mentioned skills and competences in pursuing their careers. Within the described range of investigation matters the team of researchers focused their research on providing methodology for enhancing job skills of tomorrow in the process of learning English.

Considering English as an efficient medium of instruction we can suggest the following idea: upgrading the educational content can provide endless opportunities for professional development of future specialists. To be exact, on their way of gaining professionally valuable knowledge and skills generally subdivided into two groups (soft skills and hard skills) students are to be involved in the activities that could guarantee the development of abovementioned skills. Thus, the created English elective course could serve as an example to follow. Such an English course can be organized as a 10unit course (6 to 10 hours are offered to be spent on each unit). To obtain the desired results on the way of mastering job skills of tomorrow the learning content of each unit should reflect the content of the mentioned job skills of tomorrow. The original source for organizing English learning content within the course provided could be materials available on the sites of the World Economic Forum [13] and World Skills [14].

The obtained results showed that respondents highly appreciated upgrading English learning content in accordance with the problem closely connected with the formation of job skills of tomorrow by involving them actively into the activities targeted at developing the declared set of job skills of tomorrow, to be exact: analytical thinking and innovation; active learning and learning strategies; complex problem-solving; critical thinking and analysis; creativity, originality and initiative; leadership and social influence; technology use, monitoring and control; technology design and programming; resilience, stress tolerance and flexibility; reasoning, problem-solving and ideation.

The realization of the proposed educational content is to be based on the integration of the fundamental principles of action-oriented, competence-based, mastery-based and project-based approaches under current conditions of blended learning model of educational process organization. Having analysed the students' responses as for their attitude towards the problem of top job skills development while studying at university, the team of researchers made an attempt to create the learning content of the English course on the 
Environment. Technology. Resources. Rezekne, Latvia Proceedingsofthe $13^{\text {th }}$ InternationalScientificandPractical Conference. Volume 2, 249-254

basis of the following methodological algorithm. Within the worked out algorithm the developed taxonomy of innovative techniques are to be implemented when organizing and providing the English course: 1) To organize English teaching and learning on the grounds of the integration of the fundamental principles of actionoriented, competence-based, mastery-based and projectbased approaches under conditions of blended learning model introduction. The transformed conditions of providing university education demand fundamental ideas of several approaches (the mentioned ones) as a united set that could be regarded as a new educational paradigm. And this paradigm is called to guarantee the enhancement of top job skills of tomorrow [15]. 2) To enrich English teaching and learning by means of integrating formal, non-formal and informal types of learning. We believe that such kind of integration can effectively influence the improvement of undergraduate students' top job skills of tomorrow. It will also help to share the experience gained in the process of learning English [16]. 3) To stimulate Computer Engineering and Information Technologies undergraduate students' participation in network professional communities [17; 18]. 4) To show the potential benefits of using open educational resources, on the one hand, and open professionally-oriented resources (sharing their information in English), on the other hand [19; 20]. 5) To involve Computer Engineering and Information Technologies undergraduate students in different types of activities aimed at developing top job skills of tomorrow considering their learning styles [21].

\section{CONCLUSIONS}

Computer Engineering and Information Technologies undergraduate students' attitude towards the most important job skills of tomorrow has been investigated. Scientifically backgrounded methodology for enhancing their job skills of tomorrow in the process of learning English has been provided. Practically-oriented methodological mechanism presented as a taxonomy of innovative techniques to be implemented in the process of teaching and learning English is aimed at developing top job skills of tomorrow Computer Engineering and Information Technologies undergraduate students.

\section{REFERENCES}

[1] M. Peat, C. E. Taylor and S. Franklin, "Re-engineering of undergraduate science curricula to emphasise development of lifelong learning skills”, Innovations in Education and Teaching International, vol. 42, no. 2, pp. 135-146, May 2005.

[2] P. Kommers and G. Fischer, "Lifelong Learning - More than Training”, December 1999. [Online]. Available https://www.researchgate.net/publication/2511963_Lifelong_Lear ning___More_Than_Training [Accessed Nov. 17, 2020].

[3] M. Laal and P. Salamati, "Lifelong learning; why do we need it?”, Procedia - Social and Behavioral Sciences, vol. 31, pp. 399-403, 2012. [Online]. Available: https://www.sciencedirect.com/science/article/pii/S187704281103 $\underline{0023}$ [Accessed Oct.10, 2020].
[4] World Economic Forum. [Online]. Available https://www.weforum.org/ [Accessed Dec. 11, 2020].

[5] Council Recommendation of 22 May 2018 on key competences for lifelong learning (Text with EEA relevance) (2018/C 189/01), 2018. [Online]. Available: https://eur-lex.europa.eu/legalcontent/EN/TXT/PDF/?uri=CELEX:32018H0604(01)\&from=LT [Accessed 25 Nov., 2020].

[6] These are the top 10 job skills of tomorrow - and how long it takes to learn them. 2020. [Online]. Available https://www.weforum.org/agenda/2020/10/top-10-work-skills-oftomorrow-how-long-it-takes-to-learn-them/ [Accessed Dec. 10, 2020].

[7] These are the top 10 job skills of tomorrow - and how long it takes to learn them. 2020. [Online]. Available https://www.weforum.org/agenda/2020/10/top-10-work-skills-oftomorrow-how-long-it-takes-to-learn-them//Accessed Dec. 10, 2020].

[8] These are the top 10 job skills of tomorrow - and how long it takes to learn them. 2020. [Online]. Available https://www.weforum.org/agenda/2020/10/top-10-work-skills-oftomorrow-how-long-it-takes-to-learn-them/ [Accessed Dec. 10, 2020].

[9] M. Peat, C. E. Taylor and S. Franklin, "Re-engineering of undergraduate science curricula to emphasise development of lifelong learning skills", Innovations in Education and Teaching International, vol. 42, no. 2, pp. 135-146, May 2005.

[10] M. Laal and P. Salamati, "Lifelong learning; why do we need it?", Procedia - Social and Behavioral Sciences, vol. 31, pp. 399-403, 2012. [Online]. Available: https://www.sciencedirect.com/science/article/pii/S187704281103 0023 [Accessed Oct.10, 2020].

[11] M. Peat, C. E. Taylor and S. Franklin, "Re-engineering of undergraduate science curricula to emphasise development of lifelong learning skills", Innovations in Education and Teaching International, vol. 42, no. 2, pp. 135-146, May 2005.

[12] P. Kommers and G. Fischer, "Lifelong Learning - More than Training”, December 1999. [Online]. Available https://www.researchgate.net/publication/2511963 Lifelong_Lear ning - More Than Training [Accessed Nov. 17, 2020].

[13] World Economic Forum. [Online]. Available https://www.weforum.org/ [Accessed Dec. 11, 2020].

[14] World Skills. [Online]. Available https://worldskills.org/skills/ [Accessed Nov. 14, 2020].

[15] O. Topuzov, O. Malykhin, and N. Aristova, "The Right Mix of Approaches in the English Language Teaching: Achieving Desired Learning Outcomes in the ESP Classroom”, In Proc. SIE International Scientific Conference 'May $22^{\text {nd }} 2020$, vol. 5, pp. 558-569, 2020. Doi: http://dx.doi.org/10.17770/sie2020vol5.4818

[16] O. Malykhin and N. Aristova, "Improving computer Engineering and information technologies undergraduate students' training through combination of formal, non-formal and informal learning”, In Proc. ETR International Scientific and Practical Conference, vol. 2, pp. 208-213, 2019. Doi: https://doi.org/10.17770/etr2019vol2.4113

[17] O. V. Malykhin and N. O. Aristova, "Investigation into participation activity rate of foreign languages teachers in specially focused network pedagogical communities", The New Pedagogical Review, vol. 53, pp. 227-238, 2018. [Online]. Available: http://www.educationalrev.us.edu.pl/e53/a19.pdf [Accessed Oct. 10, 2020].

[18] O. Malykhin, N. Aristova and N. Dyka, "Networked Professional Learning: The Influence on University Teachers' Self-Efficacy to Create a Positive University Climate”, In Proc. SIE International Scientific Conference May 22 20, vol. 5, pp. 200-212, 2020. Doi: http://dx.doi.org/10.17770/sie2020vol5.4825

[19] O. V. Malykhin, N. O. Aristova and V. I. Kovalchuk, "Investigation into open educational resources for learning English in developing future philologists' instrumental values”. In 
Oleksandr Malykhin, et al. Formation of Top Job Skills of Tomorrow Among Computer Engineering and Information Technologies Undergraduate Students in the Process of Learning English

Proc. SIE International Scientific Conference 'May 24th-25th 2019, vol. 3, pp. 512-526, 2019. Doi: https://doi.org/10.17770/sie2019vol3.3833

[20] . V. Malykhin, N. O. Aristova and L. M. Dybkova, "Developing Future English Teachers' Overall Communicative Language Ability: Open Educational Resources Usage" Revista Romaneasca Pentru Educatie Multidimensionala, vol. 11(4Sup1), pp. 134-155, 2019. Doi: https://doi.org/10.18662/rrem/182
[21] O. V. Malykhin and N. O. Aristova, "Learning-style based activities in boosting undergraduate students' translation skills: Agrarian sphere translators' training”, The Journal of teaching English for Specific and Academic Purposes, vol. 7, no. 1, pp. 105-114, 2019. doi: https://doi.org/10.22190/JTESAP1901105M 